\title{
Study on ozone oxidation of ammonium sulfite in aqueous solutions
}

\author{
Yi Rongjie $e^{1,2, a}$, Yi Chengwu ${ }^{1,2, b}$, Du Daolin ${ }^{1,2, c}$, Wang Huijuan ${ }^{1,2, d}$ \\ ${ }^{1}$ School of Environmental, Jiangsu University, Zhenjiang 212013, P.R. China \\ ${ }^{2}$ Jiangsu Collabrative Innovation Center of Technology and Material of Water Treatment, \\ Suzhou 215009, P.R. China \\ ayirongjie1992@163.com, ${ }^{b}$ yichengwu0943@163.com, \\ 'daolindu@163.com, ${ }^{\mathrm{d}}$ wendyjuaner@126.com
}

\begin{abstract}
Keywords: flue gas desulfurization of ammonia process; reaction kinetics; ozone; ammonium sulfite

Abstract:This paper is focused on the situation that the by-product ammonium sulfite produced in the flue gas desulfurization of ammonia process, which carried ozone oxidation experiments. In the reaction container, studied the effect of the factors as oxidation reaction temperature, $\mathrm{pH}$ value, ozone flow and initial concentration on the reaction rate of ammonium sulfite oxidation.Then, conducted the oxidation kinetics experiment under the condition that only use ozone.The results showed that ammonium sulfite and ozone concentration are both simple first-order kinetics response in the condition that only the ozone oxidation reactions.
\end{abstract}

\section{Introduction}

Ammonium sulfite is a by-product produced in the flue gas desulfurization of ammonia process, because it is easy to be disintegrated in the air, the sulfur dioxide produced in this process Cause the secondary pollution. Therefore, the process on ammonium is always the key problem in the flue gas desulfurization of ammonia process application ${ }^{[1]}$. The usual process is oxidation by use oxidant, produce the product ammonium sulfite, it is more stabilize than ammonium sulfite and it has a higher manurial effect, can be used as agrochemical. Hence, the way inverse the by-product ammonium sulfite in the flue gas desulfurization of ammonia process into diamond ammonium sulfite is the best way to popularize the desulfurization of ammonium.

Up to now, lots of research has been done on the oxidation of ammonium sulfate and homologous oxidation kinetics, in which, bubbling apparatus with catalyst is the most widely used method for oxidation. Matsuura et al has studied the homogoneous kinetics of the reaction .The esperimental findings showed that the reaction rate was zero with respect to oxygen and three-halves order with respect to sulfite ${ }^{[2]}$. This result also proved by Mishra and srivastava ${ }^{[3]}$. In the other hand, Mishra and Srivastava Neelakantan and Gehlawatand Gürkan et al studied the reaction under heterogeneous cinditions ${ }^{[4-6]}$. But they get different concluded respectly in a large range of experimental conditions. In these experiments by other researchers on the basis of any course has many drawbacks. These deficiencies are mainly in practical applications, the reaction is very slow and can not meet the requirements ${ }^{[7]}$. A complete oxidation takes several hours or more. In addition, the catalyst residue secondary pollution caused by heavy metals is needed to solve problems. In this investigation, no longer use the previous oxidizer, instead of using the advanced oxidant ozone study in a non-catalyst under conditions to minimize the secondary pollution. Ozone has a relatively high oxidation potential, which is widely used in many kinds of oxidation and 
degradation of pollutants ${ }^{[8]}$. In this study, the use of ozone for oxidation of ammonium sulfite. Examined the oxidation of ammonium sulfite initial concentration c, oxidation time $\mathrm{t}$, temperature $\mathrm{T}$, $\mathrm{pH}$, ozone flow rate $\mathrm{Q}$, and other factors on the oxidation rate and oxidation rate, and ozone oxidation method and the traditional methods of analysis and comparison, and finally simply return to the oxidation kinetics.

\section{Materials and experimental techniques}

Shown in Fig.1, oxygen cylinder oxygen into the ozone generator to produce ozone, the ozone gas flow regulating flow control, so that a certain flow of ozone into the reactor at the bottom of the aeration head, and finally with the effective volume of the drum $1.2 \mathrm{~L}$ bubble inside the reactor, a certain concentration of the oxidation of ammonium sulfite solution. Solution into the reactor inside the storage sump by a sump pump reservoir role of ammonium sulfite to the solution back into the reactor continuously. The reaction is a continuous loop process, the ammonium sulfite can be fully oxidized. To ensure a constant temperature experiment, the reactor immersed in a water bath pot. All connecting lines are Teflon tube and glass tube.

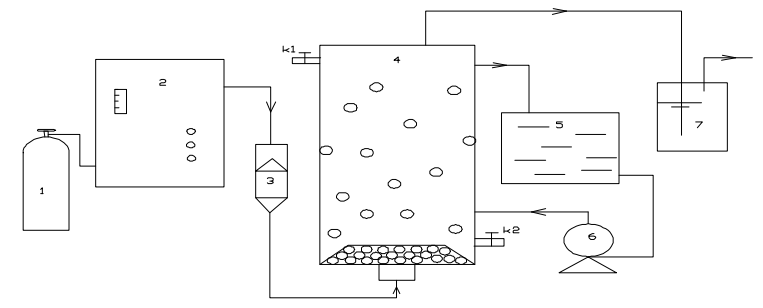

Fig.1. 1-Scheme of experimental apparatus.1-oxygen bottle, 2-ozone Generator, 3-flowmeter, 4-Reactor, 5-Storage sump, 6-pump, 7-KI fluid absorption, K1-Discharge at the entrance, K2-Discharge port

To reduce the impurities introduced during the experiment, resulting in interference experiments, using ammonium sulfite, hydrochloric acid, potassium iodide, are all of analytical grade level. Experiment with the water is deionized water, oxygen for medical oxygen.

\section{Experimental steps:}

A certain concentration of the standard solution of ammonium sulfite added to the reactor, adjust the solution temperature, $\mathrm{pH}$, flow meters and other notes of value. Start the ozone generator, ozone concentration value until after the pump the ozone gas into the bottom of the reactor drum aeration head. In operation, constantly fine-tuning the reaction temperature, ozone ventilation, adjust the reaction constant. Reaction after a certain time, measured before and after the reaction and the ammonium sulfite concentration of sulfite ions. The exhaust gas with the KI solution absorption.

Ozone concentration was determined by indigo disulphonate spectrophotometry method. determination of ammonium sulfite concentration by Iodometrie. ammonium sulfite oxidation ratuo using the following formula:

$$
X=\frac{C_{0}-C_{t}}{C_{0}} \times 100 \%
$$

$\mathrm{X}$ - oxidation ratio of ammonium sulfite.

$\mathrm{C}_{0}$ - Concentration of ammonium sulfite at the beginning of reaction.

$\mathrm{C}_{\mathrm{t}}-$ Concentration of ammonium sulfite at treatment time $\mathrm{t}$. 


\section{Results and discussion}

\section{Effect of initial ammonium sulfite concentration}

A number of experiments were performed at various sulfite concentrations to demonstrate its effect on the rate of reaction. It has been found that the oxidation rate slow down gradually with increasing sulfite concentration. This is illustrated in Fig.2. Oxidation reaction started within 20 min, oxidation is faster, then the oxidation rate became smaller and smaller. In an hour, the oxidation rate of various concentrations of ammonium sulfite was able to reach more than $90 \%$. With increasing initial concentration of ammonium sulfate, the oxidation rate decreased. When the concentration of sulfite more than $1 \mathrm{~mol} \cdot \mathrm{l}^{-1}$, the complete oxidation time of ammonium sulfute will be increased.

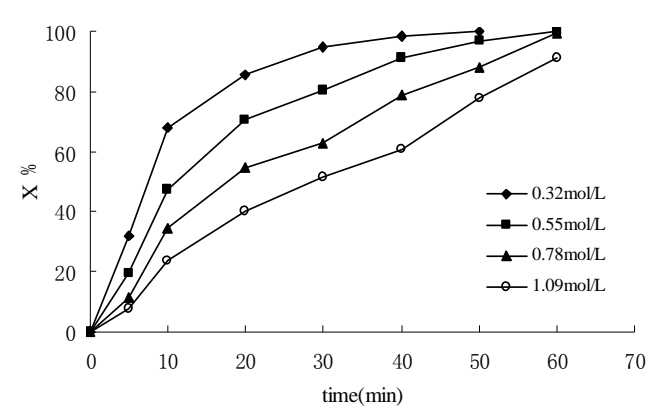

Fig. 2. Influence of initial ammonium sulfite concentration on oxidation rate. Experimental conditions: $\mathrm{pH}=7.5, \mathrm{~T}=25^{\circ} \mathrm{C}, \mathrm{Q}=500 \mathrm{ml} / \mathrm{min}$.

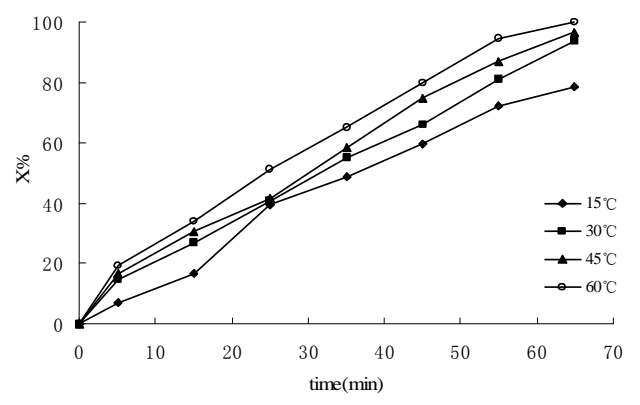

Fig.3. Effect of temperature on macroscopical oxidation of sulfite. Experimental conditions: $\mathrm{pH}=7.5, \mathrm{Q}=600 \mathrm{ml} \cdot \mathrm{min}^{-1}, C=0.8 \mathrm{~mol} \cdot \mathrm{l}^{-1}$

\section{Effect of temperature}

The effect of temperature was investigated in the range of the experimental parameters. As shown in Fig.3, the figure shows the temperature effect on the oxidation rate of ammonium sulfite. while the reaction within $5 \mathrm{~min}$, the oxidation rate of sulfite rapid increase. Subsquently, the slopes of trend line which were determine in different tempreture conditions were about unanimous. While the oxidation ratio has been boosted, the oxidation rate was changeless. This is because the temperature will lower the activation energy, but high temperatures will lead to accelerated decomposition rate of ozone, thereby reducing the solubility of ozone in water, reducing the liquid ozone concentration, so that the reaction rate decreases. Ammonium sulfite can be decomposed easily. In the case of high temperature and continuous drum gas, will make reaction system ammonium sulfite solution loss, so the reaction system temperature should not too high.

\section{Effect of pH value}

Weiss et al found that the decomposition rate of ozone in water with the $\mathrm{pH}$ of the system increases quickly. Gorbenko-Germanov ${ }^{[9]}$ found that ozone in alkaline solution will produce $\mathrm{O}_{3}$. Czapski ${ }^{[10]}$ study found that decomposition of ozone in water will produce $\cdot \mathrm{OH}$ and $\mathrm{HO}_{2} \cdot$ other free radicals. Ozone decomposition in aqueous solution will reach saturation, resulting in $\mathrm{OH}$ concenteation is no longer increase. The experiments confirmed these findings. The oxidation rates were measured at four different $\mathrm{pH}$ value in the range of 3.96-10.42 for a fixed sulfite concenteation of $0.8 \mathrm{~mol} \cdot 1^{-1}$ and at $25^{\circ} \mathrm{C}$ in the rection system. From Fig 4 is can be seen that the oxidation ratio of sulfit incareases with the increase of $\mathrm{pH}$, which is in corresponding to the oxidation ratio. However, if $\mathrm{pH}$ keep on boost when the $\mathrm{pH}$ reached about 8.53, there is no significant effect of oxidation increased. 


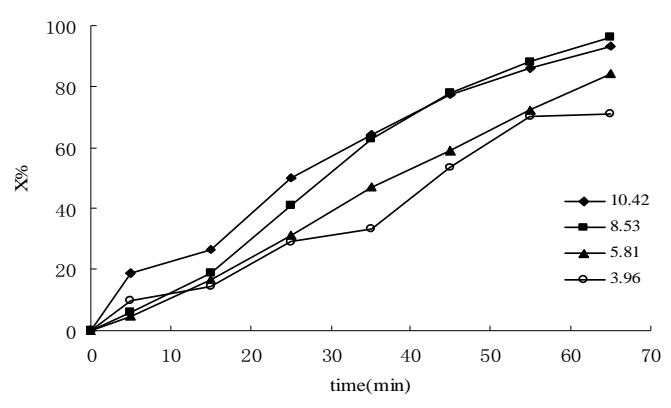

Fig.4. Effect of $\mathrm{pH}$ on oxidation rate. Experimental conditions: $\mathrm{Q}=600 \mathrm{ml} / \mathrm{min}, \mathrm{C}=0.8 \mathrm{~mol} \cdot \mathrm{l}^{-1} . \mathrm{T}=25^{\circ} \mathrm{C}$.

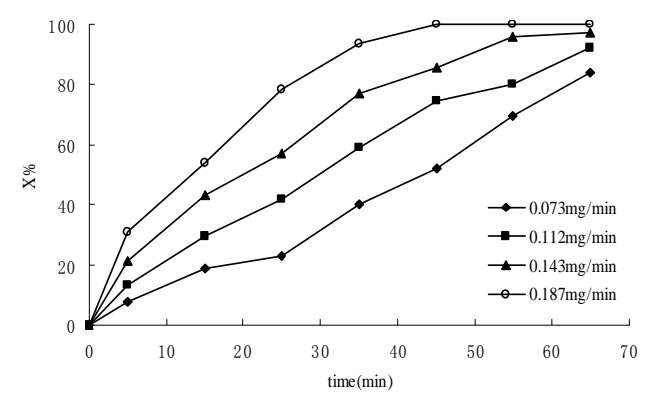

Fig.5.Effect of ozone flow on oxidation rate. Experimental conditions: $\mathrm{C}=0.8 \mathrm{~mol} \cdot 1^{-1} \cdot \mathrm{T}=25^{\circ} \mathrm{C}, \mathrm{pH}=7.5$

\section{Effect of ozone flow}

The sulfite oxidation rate with different ozone concenteation at $25^{\circ} \mathrm{C}$ are shown in Fig.5. It can be seen from the figure, with the increase in ozone ventilation, the ammonium sulfite oxidation rate increases. When the ozone flow rate reach to $0.187 \mathrm{mg} / \mathrm{min}$ and the reaction time have been finished $30 \mathrm{~min}$, the reaction system demand for ozone gradually saturated. So the ventilation without excessive ozone, or ozone will be wasted.

\section{Regression analysis of ammonium sulfite oxidation kinetics.}

\section{Directly only for the ozone reaction}

Ozone oxidation of ammonium sulfite by the following general reaction equation:

$\mathrm{O}_{3}+\mathrm{B}\left(\left(\mathrm{NH}_{4}\right)_{2} \mathrm{SO}_{3}\right) \rightarrow \mathrm{Q}_{\mathrm{s}}$

The oxidation rate of $\mathrm{B}$ can be described as follow equations:

$$
V_{B}=-d C_{B} / d_{t}=k_{O_{3}} C_{B}^{m} C_{O_{3}}^{n}
$$

Where the $V_{\mathrm{B}}$ is Oxidation rate of ammonium sulfite, $C_{\mathrm{B}}$ is theConcentration of ammonium sulfite, $\mathrm{mol} \cdot \mathrm{l}^{-1} ; \mathrm{Co}_{3}$ is Liquid phase ozone concentration, $\mathrm{mg} \cdot \mathrm{l}^{-1} ; k$ is the reaction rate constant, $1 /(\mathrm{mol} \cdot \mathrm{s}) ; \mathrm{m}, \mathrm{n}$ is the ammonium sulfite and ozone reaction order respectively.

During the experiment, as has been maintained through a lot of ozone into the reactor, ignoring the mass based on the assumption, we can consider the liquid ozone concentration remains constant, the above equation can be simplified as:

$$
V_{B}=-d C_{B} / d_{t}=k_{a b s} C_{B}^{m}
$$

Where $\mathrm{k}_{\mathrm{abs}}$ is the apparent rate constant.

Thus:

$$
k_{a b s}=k_{o_{3}} C_{o_{3}}^{n}
$$

The equation (4) both sides of the logarithmic conversion can be obtained

$$
\ln \left(-d C_{B} / d t\right)=\ln k_{a b s}+m \ln C_{B}
$$

Based on the relationship between the $\ln \left(-\mathrm{dC}_{\mathrm{R}} / \mathrm{dt}\right)$ and $\operatorname{lnC}_{\mathrm{R}}$, which can be seen from Fig.6, get the slope $m$ is the order of reaction.

Fig.6 presents the graphs of $\left(\ln \left(-\mathrm{dC} \mathrm{C}_{\mathrm{R}} / \mathrm{dt}\right)\right)$ versus $\ln _{\mathrm{R}}$ in the case of only reaction of ozone with sulfite and the ammonium sulfite concentration is in range of $0.1 \mathrm{~mol} \cdot \mathrm{l}^{-1}$ to $0.8 \mathrm{~mol} \cdot \mathrm{l}^{-1}$. As shown in Fig.6, Straight line with a slope of 1.0974 , correlation coefficient $\mathrm{R}^{2}$ is 0.9926 , which can be roughly drawn, the oxidation reactions on ammonium sulfite concentration is simple 
pseudo-first-order kinetics response.

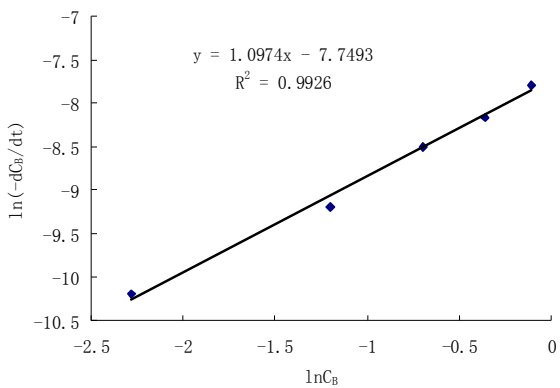

Fig.6. Determination of $\ln \left(-\mathrm{d} C_{B} / \mathrm{dt}\right)$ versus $-\ln C_{B}$ in the case of reactions of ozone with ammonium sulfite.Experimental conditions: $\mathrm{pH}=7.5, \mathrm{Q}=550 \mathrm{ml} / \mathrm{min}, \mathrm{T}=25^{\circ} \mathrm{C}, \mathrm{C}_{0}=0.8$ $\mathrm{mol} \cdot 1^{-1}$.

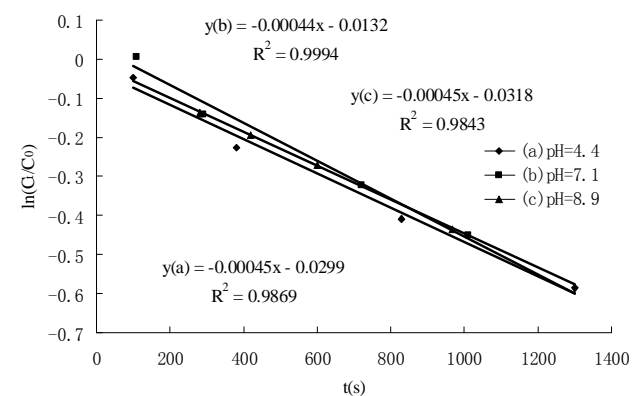

Fig.7. Kinetic analysis for apparent rate constants determination according to the pseudo first-order kinetics of the reaction of ammonium sulfite with ozone in different $\mathrm{pH}$ value. Experimental conditions: $\mathrm{T}=25^{\circ} \mathrm{C}, \mathrm{Q}=550 \mathrm{ml} / \mathrm{min}, \mathrm{C}_{B}=0.68$ $\mathrm{mol} \cdot 1^{-1}$,(a)pH=4.4,(b)pH=7.1,(c) $\mathrm{pH}=8.9$

Based on the results of the above experiment, to further confirm the inference results, it needs to be further discussed. Experiments were conducted with ozone in excess at $\mathrm{pH} 8$ as described above. ammonium sulfite ozonation was considered as a second-order reaction with first-order relative to ammonium sulfite and to ozone concentrations. The rate law for ammonium sulfite disappearance can be formulated as:

$$
V_{B}=-d C_{B} / d t=k_{a b s} C_{B}
$$

This expression can be integrated as follows:

$$
-\ln \left(C_{t} / C_{0}\right)=k_{a b s} t
$$

Thus, a graph of $\ln \left(\mathrm{C}_{t} / \mathrm{C}_{0}\right)$ versus $t$ can be confirmed the reaction of ammonium sulfite is pseudo-first-order kinetics response.

It can be seen from the fig.7, in the case of addition an inhibitor of ammonium sulfate, regardless of the solution in acid or alkaline conditions, the slope is $4.5 \times 10^{-4}$. For this reaction period, it was observed that residual concentrations versus time (Fig.7) are satisfactorily linear $\left(\mathrm{R}^{2}>\right.$ 0.984 ) in all experiments in different $\mathrm{pH}$ value, which satisfied the assumed first-order law. Thus, $\mathrm{m}$ $=1, k_{\mathrm{abs}}=4.5 \times 10^{-4}$ 。 The slope of the regression line is consistent, which further confirms the hypothesis of the reaction is one order kinetics response to concentration of ozone.

According to equation (5), to continue to explore the reaction of ozone response series.

$$
k_{\mathrm{abs}}=k o_{3} \mathrm{Co}_{3}=4.5 \times 10^{-4}
$$

The rate constant of reaction $\left(k_{3}\right)$ was calculated from the value of ozone concentration in the final sampling.

$k_{\mathrm{abs}}, R^{2}$, and $k o_{3}$ values determined for ozonation processes at various $\mathrm{pH} \operatorname{levels}\left(C_{\mathrm{B}}=0.65\right.$ $\mathrm{mol} \cdot \mathrm{l}^{-1}, \mathrm{Co}_{3}=2.89 \times 10^{-4} \mathrm{~mol} \cdot \mathrm{l}^{-1}, \mathrm{~T}=25^{\circ} \mathrm{C}$ ).

Table 1. Rate constants for the direct reaction of ammonium sulfite with ozone

\begin{tabular}{ccccc}
\hline Ozonation process & $\mathrm{pH}$ & $k_{\mathrm{abs}}\left(\mathrm{s}^{-1}\right)$ & $k o_{3}[\mathrm{l} /(\mathrm{mol} \cdot \mathrm{s})]$ & $R^{2}$ \\
\hline $\mathrm{O}_{3}$ & 4.4 & $4.5 \times 10^{-4}$ & 1.5517 & 0.9869 \\
$\mathrm{O}_{3}$ & 7.1 & $4.4 \times 10^{-4}$ & 1.5172 & 0.9994 \\
$\mathrm{O}_{3}$ & 8.9 & $4.5 \times 10^{-4}$ & 1.5517 & 0.9843 \\
\hline
\end{tabular}

The result showed that in the condition that use ozone only the oxidation reactions on ammonium sulfite concentration and ozone concentration are all simple pseudo-first-order kinetics 
response and the total reaction is pseudo-second-order kinetics response.

\section{Conclusion}

This experiment studied ammonium sulfite oxidation by ozone to explore temperature, $\mathrm{pH}$, initial concentration of ammonium sulfite, the flow of ozone and other factors in the oxidation rate of ammonium sulfite. The results show that the ozone flow rate and initial concentration of ammonium sulfite will have a direct impact on its oxidation. Although the temperature can reduce the activation energy of oxidation of ammonium sulfite, the high temperature will cause decomposition of ammonium sulfite. $\mathrm{pH}$ is a crucial factor, the direct result of ozone effects generate hydroxyl radicals in aqueous solution. In alkaline conditions which conducive to the generation of hydroxyl radicals, that can accelerate the oxidation rate of ammonium sulfite. Regression analysis in the process of oxidation kinetics, show that the concentration of ammonium sulfite and concentrations of ozone are both one reaction order of the pure ozone oxidationof ammonium sulfite. So, the reaction of response of the total reaction was first-order kinetics response.

This paper is supported by National Natural Science Foundation of China(50778083) and Science and technology support plan (social development) project of Jiangsu (BE2011732).

Corresponding auther:Yi Chengwu,E-mail:yichengwu0943@163.com

\section{References}

[1] Zhou Liming,Shi Yongyong,et al:Process optimization of flue gas desulfurization by ammonia process[J].Chemical Engineering, Vol. 4(2014), p.7

[2] Matsuura, A., J. Harada, T. Akehata and T.Shirai:Rate of ammonium sulfite oxidation in aqueous solutions [J]. Chem.Eng.Japan, Vol. 2(1969), p.199

[3] Mishra, G.C., and R.C. Srivastava:Kinetics of oxidation of ammonium sulfite by rapid mixing method[J]. Chem.Eng. Sci, Vol. 30(1975), p.1387

[4] Mishra, G.C., and R.C. Srivastava:Kinetics of heterogeneous oxidation of ammonium suifite [J]. Appl. Chem.Biotech, Vol. 26(1976), p.401

[5] Neelakantan, K. and J.K. Gehlawat:Kinetics of absorption of oxygen in aqueous solutions of ammonium sulfite[J]. Ind. Eng.Chem. Fundam, Vol. 19(1980), p.36

[6] T. Gürkan, T. Nufal,í. Eroglu:Kinetics of the heterogeneous oxidation of ammonium sulfite[J]. Chem. Eng. Sci, Vol. 47(1992), p.3801

[7] Nathalie Karpel Vel Leitner, Babak Roshani:Kinetic of benzotriazole oxidation by ozone and hydroxyl radica. Water Res., Vol. 44(2010), p.2058

[8] Pamela Chelme-Ayala, Mohamed Gamal El-Din, Daniel W. Smith: Kinetics and mechanism of the degradation of two pesticides in aqueous solutions by ozonation[J]. Chemosphere ,Vol. 78(2010), p.557

[9] Gorbenko-Germanov D S, Koziva I V,Zhur Fiz Khim:Intermediate decomposition products of ozone in alkaline aqueous media investigated by electron spin resonance[J].J. Phys.Chem., Vol. 48(1974), p.166

[10]Czapski $\mathrm{G}$ and Biehki $\mathrm{B} \mathrm{H}$ J:The formation and decay of $\mathrm{H}_{2} \mathrm{Oand} \mathrm{HO}_{2}$ in electron-irradiated aqueous solution.J.Phys.Chem.,Vol. 67(1963), p.2180 